\title{
Whose media are hostile? The spillover effect of interpersonal discussions on media bias perceptions
}

Castro, Laia ; Hopmann, David Nicolas ; Nir, L

\begin{abstract}
Since Eveland and Shah (2003) published their seminal study on the impact of social networks on media bias perceptions in the US, little has been researched about the interpersonal antecedents of hostile media perceptions. In this study we address this gap by investigating the role of safe, or like-minded, political discussions on individuals' likelihood to perceive media as hostile. We use survey data from more than 5,000 individuals in Germany. Our findings reveal that like-minded discussions increase one's likelihood to perceive media as hostile; yet, only among those more politically engaged and ideologically on the left. The significance and theoretical implications of the results are discussed in the concluding section.
\end{abstract}

DOI: https://doi.org/10.1515/commun-2019-0140

Posted at the Zurich Open Repository and Archive, University of Zurich

ZORA URL: https://doi.org/10.5167/uzh-197783

Journal Article

Published Version

Originally published at:

Castro, Laia; Hopmann, David Nicolas; Nir, L (2021). Whose media are hostile? The spillover effect of interpersonal discussions on media bias perceptions. Communications : European Journal of Communication Research, 46(4):540-563.

DOI: https://doi.org/10.1515/commun-2019-0140 


\section{Laia Castro*, David Nicolas Hopmann and Lilach Nir Whose media are hostile? The spillover effect of interpersonal discussions on media bias perceptions}

https://doi.org/10.1515/commun-2019-0140

Abstract: Since Eveland and Shah (2003) published their seminal study on the impact of social networks on media bias perceptions in the US, little has been researched about the interpersonal antecedents of hostile media perceptions. In this study we address this gap by investigating the role of safe, or like-minded, political discussions on individuals' likelihood to perceive media as hostile. We use survey data from more than 5,000 individuals in Germany. Our findings reveal that like-minded discussions increase one's likelihood to perceive media as hostile; yet, only among those more politically engaged and ideologically on the left. The significance and theoretical implications of the results are discussed in the concluding section.

Keywords: hostile media perceptions, interpersonal communication, ideology, survey, like-minded

\section{Introduction}

Time and time again, US president Donald Trump accuses the media of biased news coverage: "Well, I think the press makes me more uncivil than I am [...] I'm a very intelligent person. [...] I really believe the press creates a different image of Donald Trump than the real one", he told journalists in October 2017. Whether Trump is intelligent is not for us to determine, but the president certainly is not alone in perceiving media coverage as distorted. Extensive research shows that citizens tend to perceive the news media as biased against their own viewpoints

\footnotetext{
*Corresponding author: Laia Castro, Department of Communication and Media Research, University of Zurich, Zurich, Switzerland, E-Mail: l.castro@ikmz.uzh.ch.

David Nicolas Hopmann, Centre for Journalism, Department of Political Science, University of Southern Denmark, Odense, Denmark, E-Mail: dnh@sam.sdu.dk.

Lilach Nir, Communication and Political Science, The Hebrew University, Jerusalem, Israel, E-Mail: Inir@mail.huji.ac.il.
} 
(Chaffee and Mutz, 1988; Dalton, Beck, and Huckfeldt, 1998; Giner-Sorolla and Chaiken, 1994; Mutz and Martin, 2001; Vallone, Ross, and Lepper, 1985).

Understanding hostile media perceptions is a major task for many reasons. Gauging the role of audiences' reactions and perceptions to mediated political messages is especially relevant in current segmented and partisan media environments, where opportunities to self-select political content have proliferated (Feldman, 2011). Explaining perceptions of media hostility is also relevant because they have been linked to highly relevant political attitudes and behavior: decrease of trust in media and political institutions (Hansen and Kim, 2011); increased feelings of isolation (Mutz, 2002), anger and lowered political efficacy (Tsfati and Cohen, 2005), reluctance to express views (Hwang, Pan, and Sun, 2008), and political mobilization, by way of triggering corrective actions designed to change a perceived hostile status quo (Rojas, 2010).

Are some citizens more likely to perceive the media as hostile than others? Are all individuals' hostile perceptions equally affected by their peers? Previous research has shown that Republicans in the US are more prone to distrust the media or perceive hostile media bias than Democrats (Lee, 2005; Mutz and Martin, 2001), especially when they discuss politics with like-minded peers (Eveland and Shah, 2003).

Much less is known about the impact of political discussion on perceived media bias among people with different political preferences and attitudes outside the US context. The US is a very particular case since public perceptions of a liberal media bias have been the object of heated discussions among politicians, political pundits, and journalists for decades (Eveland and Shah, 2003; Strömbäck and Dimitrova, 2006; Watts, Domke, Shah, and Fan, 1999). In this study, we draw on individuals surveyed by the German Longitudinal Election Study in 2013 (N= 5,353). The larger significance of the German case is illustrated by several features of its media structure. Like most western European democracies, Germany has a strong public-service broadcasting system that adheres to values of political balance and neutrality which spill over into private TV channels (Reinemann, Stanyer, \& Scherr, 2016). Power-sharing political systems like Germany's are the norm in the majority of European countries, and hold the potential for enhancing people's perceptions of media representativeness and inclusiveness (Nir, 2012; Wessler and Rinke, 2014) while also contributing to familiarizing citizens with differing (and by extension more hostile) political views.

In this paper, we argue that being embedded in like-minded or safe political discussions reinforces individuals' political predispositions and decreases their willingness to tolerate political disagreement. The result is an increase of perceived ideological gaps between one's surrounding social networks and more distant and heterogeneous media environments, which are perceived as politi- 
cally hostile (Huckfeldt, Johnson, and Sprague, 2004). Those more activist and partisan individuals should be more prone to perceiving such gaps since they tend to be more passionate about their political beliefs and to judge information more defensively (Giner-Sorolla and Chaiken, 1994; Gunther and Liebhart, 2006; Vallone et al., 1985).

Our study has also focused on the impact of ideology on media bias perceptions. Departing from mixed evidence on the impact of pre-existing political views on tolerance towards incongruent information and perceptions of an opinion climate (Huckfeldt, 2001; Mutz and Martin, 2001; Sidanius, 1985), we ask whether leftists or rightists are more or less likely to experience media as hostile. We rely on a series of ordered logistic regression models with perceived hostile media bias as dependent variable, safety of political discussions and left-right self-placement as well as strength of party identification as independent variables of theoretical interest. Results show an interaction effect between safety of political discussions and ideology. Not only do those more engaged, partisan, and leftist individuals experience hostile bias perceptions in greater numbers but also their discussions within like-minded networks is more positively correlated to perceived hostile media bias the more leftist an individual is. Additionally, we find evidence that more politically sophisticated individuals tend to perceive media as hostile when talking to people with whom they agree. The results complement previous US findings and highlight the importance of both individual and situational characteristics in explaining perceived media bias.

\section{Perceived media bias, interpersonal communication, and ideology}

Hostile media perceptions (or HMP) have long been object of study among communication scholars. Since Vallone et al. (1985) conducted their seminal experiment to test what they called a hostile media phenomenon among pro-Israeli and pro-Arab students, a wide array of studies have investigated how people on different sides of a policy issue perceive neutral media coverage as hostile (e.g., Gunther and Schmitt, 2004; Schmitt, Gunther, and Liebhart, 2004). As Weeks, Kim, Hahn, Diehl, and Kwak (2019) note, perceptions of hostile media bias are particularly puzzling considering that previous meta-analyses did not find strong support for the assumption that news media favor one political camp over the other. However, both encounters with completely balanced information on any political issue or people judging news coverage in exactly the same way are relatively rare (Arlt, Dalmus, and Metag, 2019). In other words, outside of the lab, 
citizens might be making substantially different media choices (Goldman and Mutz, 2011).

This possibly explains why more recent survey-based approaches have examined HMP by looking at people's perceptions of how biased the media generally are, irrespectively of their actual slant (Barnidge and Rojas, 2014; Eveland and Shah, 2003; Rojas, 2010). After all, as Gunther and Christen (2002) put it, they can perceive the media as being unfriendly or unfavorable relative to their political rivals, even when they are being exposed to like-minded sources of political information. Perceptions of media bias may or may not mirror actual biases and merely lie in the eye of the beholder.

Other studies have estimated HMP by measuring the distance between personal viewpoints and the perceived ideology of the media one frequently uses. This approach comes closer to original studies on media perception in the experimental tradition insofar as the studies rely on the media that people are actually exposed to, in contrast to perceptions on the media in general. It also presumably holds higher levels of external validity since it builds on media one frequently uses (Bachl, 2016; Gunther, 1992).

Inspired by the survey-based and experimental traditions outlined above, in this study we conceptualize hostile media perceptions (or hostile media bias perceptions) ${ }^{1}$ as "phenomena in which people perceive media as biased against their point of view" (Barnidge and Rojas, 2014, p. 137), irrespective of how balanced the actual media coverage is. To operationalize hostile media perceptions, we also consider the "perceived ideological distance between the self and the media" (Barnidge and Rojas, 2014, p. 138; see also Rojas; 2010, Wojcieszak, 2010) people frequently select and use. Therefore, our approach is not only more generalizable than experimental research using forced conditions, but may also hold higher levels of internal validity than survey-based studies using people's perceptions of media in general since it relies on media outlets respondents are actually exposed to on a frequent basis (Bachl, 2016).

In this vein, several other studies posit or show that perceptions can differ across media types, their reach, or their level of partisanship (Arpan and Raney, 2003; Gunther and Liebhart, 2006; Gunther, Christen, Liebhart, and Chia, 2001; Hansen and Kim, 2011).

Much less has been contended on how the nature of people's political discussions shape individual levels of hostility towards the media. Indeed, previ-

1 Hostile media perceptions and hostile media bias perceptions are used interchageably throughout this article (see Bachl, 2016; Eveland and Shah, 2003; Huge and Glynn, 2010 for studies also using perceived media bias, perception of hostile media coverage, hostile media phenomenon, and hostile media effect interchangeably). 
ous research demonstrates that people tend to rely on their close surroundings and most trusted others to acquire and process political information (Chaffee and Mutz, 1988; Klofstad, McClurg, and Rolfe, 2009; Robinson, 1976). From that it follows that the way one perceives news media messages depends to a great extent on how they are adopted by one's interpersonal encounters (Hardy and Scheufele, 2005). As Druckman, Levendusky, and McLain (2017) posit, discussing politics with fellow partisans can dramatically moderate effects of partisan media messages, making such messages more or less persuasive.

Despite the ability of social environments to shape people's processing and understanding of mediated information, previous studies have largely neglected the role of interpersonal communication on hostile media bias perceptions. Nevertheless, we have good reasons to believe that people with whom they frequently discuss politics play an important role for their predisposition to perceive the media as hostile.

Being engaged in homogeneous, or safe, political discussions has been associated with perceived media bias against one's own views (Eveland and Shah, 2003). What can explain such a relationship? People actually encounter more diverse views through the media than through their social interactions (Chaffee, 1982; Gentzkow and Shapiro, 2011; Mutz and Martin, 2001), whose conflicting viewpoints can drive social discomfort (Huckfeldt et al., 2004) and a fear of taking sides because of social accountability pressures (e.g., Mutz, 2002). Perhaps more importantly, people tend to overestimate the level of agreement within their networks and underestimate the level of agreement with their frequent media diets (Mutz and Martin, 2001). This so-called false consensus effect or distortion (Ross, Greene, and House, 1977) that makes people amplify the commonness of one's and others' viewpoints increases the gap between perceived ideological closeness in interpersonal communication as compared to mediated communication. Moreover, people surrounded by like-minded others tend to be less tolerant of divergent viewpoints (Price, Cappella, \& Nir, 2002). Homophily in political discussions reinforces attitudes and makes individuals perceive that something important is at stake and to be preserved. That individuals' social contexts are highly homogeneous and cross-cutting, or non-like-minded views less tolerable, can in turn make people feel "strangely divorced" from the outside world (Huckfeldt et al., 2004, p. 29). All in all, individuals in homogeneous networks are likely to perceive any dissonant or dissenting argument as greatly distant, foreign, and hostile. Therefore, we expect to find that:

H1: Hostile media perceptions are stronger among those embedded in like-minded, or safe, discussions. 
By the same token, perceptions of hostile bias should be higher among strong partisans (Eveland and Shah, 2003; Giner-Sorolla and Chaiken, 1994). Previous research attests to the assumption that those who hold higher levels of attitude extremity and ideological or partisan strength, irrespective of the direction, tend to perceive news media as hostile (Arlt et al., 2019; Hwang et al., 2008; Matthes, 2013; but see mixed evidence in Gunther and Christen, 2002). As the prior attitude effect hypothesis posits (Taber and Lodge, 2006), people have difficulties to put aside "their prior feelings and prejudices when evaluating evidence, even when pro and con arguments have been presented to them in a balanced manner" (p. 760). In this vein, strong partisans are more likely to categorize information as opposed to their own views (Hansen and Kim, 2011; Vallone et al., 1985) and judge political information more defensively. Partisans are also particularly concerned about others' opinions and fear that biased information decisively affects less informed, vulnerable, or neutral audiences (Gunther and Liebhart, 2006). As Gunther and Storey (2003) showed, presumed media influence on others amplifies hostile media perceptions. Also, those with a strong in-group identification (attachment and sense of belonging to a group that is believed to hold homogeneous views) experience stronger hostile media perceptions. The impact of strong attachment to a group is even amplified when they sense their group has "a lower status in society than the out-group" (Hartmann and Tanis, 2013, p. 543). Overall, we expect to find higher levels of hostile media perceptions among individuals exposed to homogeneous political discussions, and, in particular, among strongly partisan individuals embedded in like-minded networks reinforcing their existing views.

Hence, we anticipate that:

H2: The more partisan individuals are, the higher their likelihood to experience hostile media perceptions.

H3: Hostile media perceptions are stronger among more partisan individuals who have safe political discussions.

Previous literature provided mixed or inconclusive evidence on whether the direction of the ideological leaning makes an individual more or less likely to experience hostile media perceptions. Eveland and Shah (2003) showed that US Republicans are more likely to experience hostile media perceptions than Democrats. The authors contended that their findings can be explained by a particular climate of opinion in the US: an across-the-board perception of liberal media bias among the political establishment and US journalists. Indeed, when people believe that particular groups or institutions are ideologically distant, they also 
tend to believe these institutions are more biased. This mechanism has been shown to be salient among Israeli undergrad students, for example, who perceive their professors are more left-leaning than themselves because of a widespread belief that academic instructors are predominantly leftist (Yair and Sulitzeanu-Kenan, 2015).

However, other studies in political psychology showed that, in general, being extreme rightist is negatively correlated to cognitive complexity (Sidanius, 1985). On average leftists are more often critical thinkers, and have a greater need for cognition (Jost, Glaser, Kruglanski, and Sulloway, 2003). This would explain why left-leaners tend to have more politically diverse media diets (Mutz and Martin, 2001), which in turn may be conducive to a greater perception that media voice hostile political views. Furthermore, the social networks of leftists may also be more politically heterogeneous, since those individuals with greater need for cognition tend to value expertise rather than safeness when choosing their political discussants (Huckfeldt, 2001). Being surrounded by experts increases the influence of political discussions (Huckfeldt, 2001), which may, in turn, decrease ideological gaps between one's social networks and media diets, and perceived views of hostile media. We therefore make no strong prediction of the effects of individual ideology and formulate the following research question:

RQ1: Are left- or right-wing individuals more prone to hostile media perceptions?

\section{Method}

To test our hypotheses, we relied on data from the German Longitudinal Election Study (GLES) 2013 (N=5,353). Survey data have been used in the past to investigate individual media bias effects (e.g., Tsfati, 2007) and potential implications of heterogeneity in political discussion networks (e. g., Eveland and Hively, 2009). Data on a national representative sample were collected between August and November 2013. Data collection was done via CATI. The response rate for the pre-election wave was $15.8 \%$, that for the post-election wave, $67.9 \% .^{2}$ In our analyses, we used ordered logistic regression models with hostile media bias perceptions as dependent variable and individual (strength of party identification, ideology) and situational factors (safety of political discussions) as well as several crosslevel interactions (ideology and strength of party identification with safe/dangerous/neutral discussions) as main independent variables of theoretical interest.

2 For further details on question wording and coding, see Rattinger et al., 2014. 
Hostile media perceptions were assessed using two survey items. We used questions tapping the party preference of each individual and the perceived party bias of each news outlet this individual watched/read at least once a week (see Bachl, 2016 or Barnidge and Rojas (2014) for similar approaches). We first coded each individual's party preference and labeled each party as leftist or rightist based on public perceptions of that party's ideology. Second, we considered (up to) three parties an individual perceived were being favored by each of their frequently used media outlets and computed an average perceived ideology for each outlet on a 3-point scale (rightist, leftist, or neutral). Third, we averaged each individual's media bias perceptions by the number of media outlets she or he used at least once a week. Fourth and last, we created a variable where a value of -1 was assigned to those who perceived their frequent media diet as close to their political camp (either left or right), 0 to those who perceived it as neutral, and 1 to those who perceived it as favoring the opposing political camp $(M=0.06$, $S D=0.53$ ) (see Guess and Coppock, 2018 for analogous scaling applied to the measurement of exposure to counter-attitudinal information). A more succinct description of the operationalization of this variable is shown in Table 1, and a toy example is provided in the Appendix.

Table 1: Hostile media perception scores.

\begin{tabular}{c|c|c|c} 
Own party preference & $1 \leq \mathrm{MBP}<2$ & $2<\mathrm{MBP} \leq 3$ & $=2$ \\
\hline Leftist & $-1(\mathrm{~N}=260)$ & $1(\mathrm{~N}=343)$ & $0(\mathrm{~N}=1484)$ \\
\hline Rightist & $1(\mathrm{~N}=845)$ & $-1(\mathrm{~N}=490)$ & $0(\mathrm{~N}=1440)$ \\
\hline Note: Media Bias Perceptions (MBP) $1=$ Leftist $2=$ Neutral $3=$ Rightist
\end{tabular}

Homogeneity in political discussions was constructed from three items that asked each respondent about their party preference, with whom they discussed most about politics, and which party they thought this person would vote for in the following federal election. Each respondent's main discussants were coded as leftist, rightist, or neutral based on their voting intention. We then created three variables accounting for the absolute difference between each respondent and the average party support of their two main discussants, which we labeled "safe", "dangerous", and "neutral" political discussions. Answers ranged from 0 to 1 $(M=0.39, S D=0.42)$. We accounted for political discussions with a relatively small discussant network since GLES asked a series of questions on frequency of political talk and perceived vote preference of two main discussants. This approach differs from other standards and survey items asking respondents to name up to four discussants (e.g., 2000 ANES). Whereas one could argue that political talk with a lower number of discussants may be a measure of close-tie political discus- 
sions, a closer look at a GLES question tapping the degree of closeness to people's frequent political discussants reveals a great deal of variation in the respondents' distribution. As an example, more than $40 \%$ of respondents reported discussing politics with people other than their spouse/partner or a relative for the first discussant, and nearly $50 \%$ for the second discussant.

Strength of party identification was measured by asking participants how strongly they were inclined to support their preferred party $(M=2.47, S D=1.87)$. Responses were coded on a scale from 0 to 5 (where $0=$ no party identification, $5=$ very strong party identification). Political ideology was constructed from an item that measured the participants' self-reported ideology on a left-right scale from 1 to 11 (higher=right) $(M=4.35, S D=2.2)$.

In addition, we considered further individual differences in our analyses. Previous research shows those more politically interested, knowledgeable, and mobilized seek out ideologically diverse media information (Garrett, 2009) and tend to experience hostile bias perceptions in greater numbers (Rojas, 2010). We therefore controlled for political sophistication, which was a combined measure of political knowledge and political interest, operationalized from an item that probed "Which of the two votes is decisive for the relative strengths of the parties in the Bundestag?" and another one probing "How interested in politics are you?" ( $0=$ not at all to $4=$ =very interested; $M=3.04, S D=1.19$ ), respectively (see De Vreese and Boomgaarden, 2006 for a similar approach).

We accounted for levels of self-reported media attention when watching TV news and reading political information, since Dalton et al. (1998) find hostile media bias perceptions to be higher among those who paid less attention to (the 1992 US presidential) election news coverage. Habitual media attention was constructed as an index by averaging two items, attention to news on television and newspapers; responses were $1=$ very carefully, $2=$ carefully, $3=$ not so carefully, 4=not carefully at all $(M=1.67, S D=0.68)$. Responses were re-coded to an inverted index, with higher scores reflecting stronger media attention to news. Additional socio-demographics such as gender (51.42\% of respondents were female), education (1-5 scale; $M=3.66, S D=1.19$ ), and age (the average age was 53.3 years old) were included in our regression models as well.

We additionally examined the size of respondents' political discussion networks since the likelihood to encounter disagreement in such networks increases with each additional discussant (Granovetter, 1973; Mutz and Mondak, 2006), which in turn may serve as a benchmark for individuals to assess like-mindedness in their media diets. Also, network size has been shown to have a positive relationship with other potential predictors of hostile media bias perceptions such as political engagement and knowledge (Eveland and Hively, 2009). Network size was measured by asking respondents how many people they talked to about pol- 
itics in an average week, on a range from 0 to $20(M=2.77, S D=4.07)$. Frequency of political discussions was also considered by measuring how many days a week participants talked about politics with other people, where $0=0$ days a week, $7=7$ days $(M=1.57, S D=1.9)$. As with network size, engagement in political discussions is a frequent predictor of political learning, knowledge, and interest (Eveland, 2004).

Additionally, we ran separate analyses for newspapers and TV since perceptions of media bias may vary from source to source. Previous research demonstrates that newspapers hold higher levels of trust and credibility among the public than TV channels (Flanagin and Metzger, 2000). Previous literature also shows that German newspaper coverage is highly opinionated (Bachl, 2016), all of which can affect individuals' media bias perceptions.

\section{Results}

Are safe discussion networks associated with hostile media bias perceptions? And can these safe networks affect perceived hostile media for ideologues on both sides? Table 2 shows four ordered logistic regression models (1a-d). We thereby tested whether being embedded in like-minded social networks (H1), being more partisan (H2) and leftist (RQ1), make individuals more likely to perceive hostile media bias and whether individual strength of party identification amplifies the impact of safe discussions on hostile media bias perceptions (H3).

Findings provide partial support for our hypotheses. Evidence of the role of discussing politics in safe or like-minded social settings was inconclusive, with some coefficients showing hostile effects (H1), whereas others coefficients showing the opposite trend for different levels of the other component variables in the interaction terms. Strength of party identification positively correlated with hostile media bias perceptions across 1a-d. We found no support for $\mathrm{H} 3$ that there is an interaction between partisanship and safe discussions (Model 1c). That is, individual partisanship strength does not amplify the impact of like-minded discussions on hostile media perceptions, as the literature underpinning H3 suggests.

By contrast, all models without exception showed that being a leftist increases one's likelihood to perceive media as hostile (RQ1). Indeed, we found hostile bias perceptions to hold the strongest correlations with ideology ${ }^{3}$. As an example, a

3 As robustness checks, we ran additional analyses (not shown) with a further measure accounting for the left-right leaning of each respondent's preferred party (vote to leftist/rightist party). 
Table 2: Prediction of hostile media bias perceptions.

\begin{tabular}{|c|c|c|c|c|}
\hline & Model 1a & Model $1 \mathrm{~b}$ & Model 1c & Model 1d \\
\hline Variable & $\mathrm{b} / \mathrm{se}$ & $\mathrm{b} / \mathrm{se}$ & $\mathrm{b} / \mathrm{se}$ & $\mathrm{b} / \mathrm{se}$ \\
\hline Ideology (Right) & $-1.28 * * *(.02)$ & $-.09 * * *(.02)$ & $-.13 * * *(.02)$ & $-.13^{* * *}(.02)$ \\
\hline Party ID strength & $.07 * *(.03)$ & $.07 * *(.03)$ & $.07 *(.03)$ & $.07 * *(.03)$ \\
\hline Political sophistication & $.09 *(.04)$ & $.09 *(.04)$ & $.09 *(.04)$ & $-.01(.05)$ \\
\hline News media attention & $.16^{* *}(.06)$ & $.16^{* *}(.06)$ & $.16^{* *}(.06)$ & $.16^{* *}(.06)$ \\
\hline Female & $.08(.07)$ & $.08(.07)$ & $.08(.07)$ & $.08(.07)$ \\
\hline Education & $-.03(.03)$ & $-.03(.03)$ & $-.03(.03)$ & $-.03(.03)$ \\
\hline Age & $.01 * * *(.00)$ & $.01 * * *(.00)$ & $.01 * * *(.03)$ & $.01 * * *(.00)$ \\
\hline Frequency of pol discussions & $.02(.02)$ & $.02(.02)$ & $.02(.02)$ & $.02(.02)$ \\
\hline Network size & $.00(.01)$ & $.00(.01)$ & $.00(.01)$ & $.00(.01)$ \\
\hline Discussion safety & $.11(.11)$ & $.40 *(.19)$ & $.03(.34)$ & $-.87 * *(.28)$ \\
\hline Discussion danger & $.16(.14)$ & $.16(.14)$ & $.16(.15)$ & $.18(.14)$ \\
\hline Discussion safety*ideology & & $-.07 \#(.04)$ & & \\
\hline Discussion safety*party strength & & & $.02(.34)$ & \\
\hline Discussion safety*pol sophistication & & & & $.29 * * *(.08)$ \\
\hline threshold(1) & $-1.24(.23)$ & $-1.11(.24)$ & $-1.25(.23)$ & $-1.57(.25)$ \\
\hline threshold(2) & $2.15(.23)$ & $2.28(.24)$ & $2.15(.24)$ & $1.83(.25)$ \\
\hline $\mathrm{N}$ & 3849 & 3849 & 3849 & 3849 \\
\hline $\operatorname{chi} 2 / \mathrm{df} / \mathrm{p}$ & $162.36 / 12 / .00$ & $165.97 / 13 / .00$ & $162.42 / 13 / .00$ & $176.81 / 13 / .00$ \\
\hline McFadden's pseudo R2 & .025 & .025 & .025 & .027 \\
\hline
\end{tabular}

one-unit shift to the left of the ideological scale resulted in a 1.28 increase in the ordered log-odds of experiencing high levels of hostile media bias perceptions, holding the other variables constant at their means. Put differently, for a one-unit decrease on the left-right scale, the odds of experiencing high as compared to low levels of hostile perceptions are .88 times greater, holding the other variables constant. Interestingly, we also found that extreme leftists experience a higher degree of hostile media bias perceptions when surrounded by like-minded others in political discussions (see Figure 1 and Model $1 \mathrm{~b}$ in Table 2).

Figure 1 illustrates the relationship between discussion safety and hostile media bias perceptions among individuals with different left-right ideological positions. The figure shows a decrease in the marginal effect of engagement in safe discussions on perceptions of hostile bias the more right-of-center an individual is. The effect of discussion safety on hostile media perceptions is $8 \%$ higher for individuals who score 0 in the left-right scale (extreme leftists) and decreases to $3 \%$ for those who score 4 (relative to those scoring 3 ). The effect remains non-significant and invariant for individuals who place themselves on

Results with this variable confirm patterns found in models 1a to 1d, namely: voting for a leftist party significantly increases one's likelihood to perceive media as hostile; strength of party identification positively correlates with hostile media perceptions (although non-significantly); no support for an effect of like-minded discussions among strong partisans on perceived media bias. 


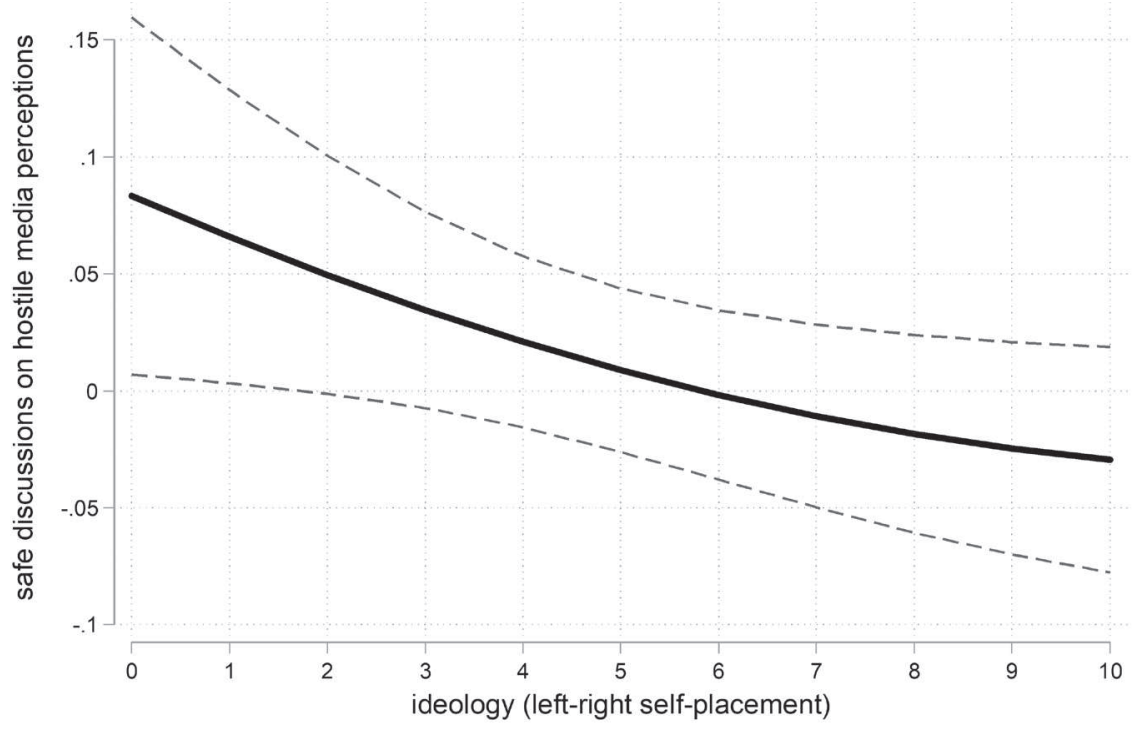

Figure 1: Average marginal effects of the safety of political discussions on hostile media bias perceptions, by left-right self-placement (10=Right).

Note: Effect sizes on hostile perceptions for each point in the left-right scale with $95 \% \mathrm{Cl}$.

more rightist positions on the left-right spectrum (results not shown, available from authors).

Additionally, political sophistication is positively linked to hostile media bias perceptions in three of four models. Perhaps most interestingly, we found evidence that holding high levels of political interest and knowledge (political sophistication) and being in congruent social networks encourages perceptions of hostile media bias. Figure 2 in the Appendix shows the relationship between discussion safety and hostile media bias perceptions by different levels of political sophistication. Safe discussions play a significant role in explaining hostile perceptions for those with the highest and lowest scores in sophistication. The effect of safe discussions on hostile perceptions is positive and significant for high levels of political sophistication. For those scoring low, the effect is negative and significant. The implications of these findings are discussed in the concluding section.

The inclusion of further situational variables accounting for the role of political discussions for our analyses yielded mixed results. Size of discussion networks, or frequency with which individuals engage in political discussions, have no impact on bias perceptions. Additionally, we found that news media attention and age significantly predict hostile media bias perceptions. 
We also distinguished between media sources and ran separate analyses for newspapers and TV news, since perceptions of bias may vary from one medium to the other (Bachl, 2016; Flanagin and Metzger, 2000). Results of a t-test comparing average levels of hostile bias perceptions in newspapers and TV news bulletins revealed no statistically significant differences between sources. We also compared the results of our regression models on hostile media bias perceptions separately for each medium. The effects of network safety and ideological leaning on hostile bias perceptions were not substantially different for newspaper as compared to TV news exposure.

\section{Discussion}

Previous research has established the contribution of hostile media bias perceptions to the willingness to engage in political discussions (Barnidge and Rojas, 2014; Hart, Feldman, Leiserowitz, and Maibach, 2015), to speak up (Hwang et al., 2008), or to increased political action (Borah, Thorson, and Hwang, 2015). However, since Eveland and Shah (2003) published their study on the impact of interpersonal communication on perceived media bias in the US, little has been investigated about social environments as antecedents of hostile media effects (Perloff, 2015).

In this study, we aimed to fill the void by investigating the extent to which engaging in safe, or like-minded, political discussions makes individuals more or less likely to perceive a hostile media bias. Previous research has shown that pretty much every aspect of citizens' political attitudes, behavior, and knowledge is heavily influenced by social environments (for overviews, see, e. g., Huckfeldt, 2007; Schmitt-Beck and Lup, 2013) and, hence, there is no reason to assume that media bias perceptions would not be. We considered attitudes (strength of party identification, ideology) and discussion agreement as well as other factors (political sophistication, network size, frequency of political discussion) with the potential to explain how citizens process and understand political information via the media, thereby going beyond previous studies that only take into account individual-level explanations (Matthes, 2013; Oh, Park, and Wanta, 2011). We also made use of data on the perceived party preference of outlets, which provides sources' general ideological outlook and is less context-sensitive than previous approaches relying on issue position (Hartman and Tanis, 2013; Wojcieszak, 2017).

Whereas talking politics with like-minded others does not seem to have an across-the-board effect on hostile media perceptions, our results show that polit- 
ically homogeneous discussions may be linked to hostility towards the media among those more partisan and to the left of the political spectrum. Our findings show that those more leftist, partisan, and politically sophisticated are more likely to experience hostile media effects; most importantly for the purpose of this study, being in like-minded social settings makes (extreme) leftists and also politically knowledgeable and interested individuals more prone to perceive media as hostile.

The results have various theoretical implications and point at two promising avenues for future study. Firstly, diverging from previous findings in the US we show that respondents in like-minded political discussions are more likely to experience media as biased against their views the more to the left they are on the political spectrum. We used data collected in Germany during the 2013 federal election campaign. Until then, the conservative CDU/CSU were in office, in coalition with the FDP. Scholars have lengthily discussed whether hostile media bias is a result of self-categorization processes, previous negative beliefs about media, and ideological predispositions (as posited by Giner-Sorolla and Chaiken, 1994; Kim, 2016; Reid, 2012; Vallone et al., 1985) or instead mirrors actual biases in media's provision of political information (as shown by Arceneaux, Johnson, and Murphy, 2012; Coe et al., 2008). Against this background, the question arises as to whether our findings are the product of leftists' individual idiosyncrasies that are conducive to hostile media effects (strong need for cognition, critical thinking), as argued above. This thesis is supported by the fact that those GLES respondents scoring high in political sophistication, and, by extension, more prone to have ideologically diverse media diets and engage in defensive processing (Castro, Nir and Skovsgaard, 2018; Rojas, 2010; Taber and Lodge, 2006; Zaller, 1992) were also found to experience high levels of hostile media perceptions when embedded in like-minded discussions. Alternatively, results may be due to a journalistic tradition that grants information bonuses to political incumbents (see, for the German case, Schönbach and Semetko, 2000; Schönbach, Ridder, and Lauf, 2001). The possibility of actual biases is also supported by the fact that those scoring low in political sophistication (and least likely to be exposed to political information) are also less hostile toward the media or, more directly, by the positive relationship between individual media attention and perceived hostile media bias found in our analyses. Further longitudinal and cross-national studies using survey and media content data are nevertheless needed to confirm whether, as with German media incumbency bonuses or with US public perceptions of liberal bias, specific contextual variables may be also at play, above and beyond individual predispositions and interpersonal factors.

Secondly, future cross-national approaches may also help to discern spillovers from interpersonal communication to perceptions of media bias in a 
more precise way. Should we expect homogeneous social networks to have the same impact everywhere? Once again, our results differed from those in the US, where like-minded social environments alone seem to play a significant role in increasing hostile bias perceptions. This discrepancy can be simply due to the use of different approaches to operationalize hostile media bias perceptions. For example, whereas we relied on a survey item that measured subjective perceptions of bias in frequently used particular media outlets, Eveland and Shah (2003) used an item tapping the extent to which individuals believed most news media in the US were biased against their own viewpoints. ${ }^{4}$ By capitalizing on country differences, however, future analyses could offer more substantial and theoretically-grounded explanations of the variability in hostile media bias effects. For instance, future research may uncover the extent to which different levels of media and political segmentation across countries (higher vs. lower diversity of media platforms, power-concentrating/majoritarian vs. power-sharing political systems with proportional representation) can make citizens more or less familiar with (and by extension sensitive to) non-like-minded, or cross-cutting, political views.

The current study is not without limitations. The most obvious caveat follows from the use of cross-sectional data. Though previous studies on political discussion networks and hostile media bias perceptions have similarly employed survey data from one country at one point in time (Eveland and Hively, 2009; Tsfati, 2007), our methodological approach advises caution regarding causality claims. Further experimental research might complement our study and explain differences in perceptions on media content, albeit previous meta-analyses showed that surveys present more consistent results than experiments (Hansen and Kim, 2011; Savage, 2004).

Second, from our results no inference can be made on perceptions of media bias among individuals discussing politics online. Due to data availability constraints, we could only consider political exchanges within offline discussions

4 Our results might have been more compelling had we had taken into account either people's perceptions on the media as a whole or outlets they do not normally use. However, our approach goes in line with previous experimental and survey research that tests levels of hostility towards content that individuals have actually been exposed to (e. g., Vallone et al., 1985) and considers perceived media hostility as "perceived ideological distance between the self and the media" (Barnidge and Rojas, 2014, p. 138; see also Rojas, 2010; Wojcieszak, 2010). The generalizability of our results is also greater than other survey-based studies since we use people's perceptions on media outlets they frequently select and use. This is also important in analyzing effects of hostile media perceptions. Gauging individuals' perceptions of bias on their frequent media diet may also contribute to better explaining the impact of such perceptions on their attitudes and behaviors. 
with up to two discussants (see Footnote 2 for a more detailed account of the nature of such discussions as found in GLES data). Recent research shows that reliance on social media for news exacerbates perceptions of media bias (Rojas, Barnidge, and Abril, 2016). Further research needs to tap into dynamics of media bias perceptions among people discussing politics in social media, since these platforms offer greater opportunities to self-select but also fewer chances to avoid potentially hostile political views (Barberá, Jost, Nagler, Tucker, and Bonneau, 2015; Flaxman, Goel and Rao, 2016); allow citizens to rely on broader networks of experts and political junkies; facilitate heated and even uncivil political discussions with non-likeminded others (Theocharis, Barberá, Fazekas, Popa, and Parnet, 2016); or are catalyzers of perceptions of media hostility by connecting candidates (and their negative and emotional campaigning) with their enthused partisan, and/or angry supporters in more direct ways (Weeks et al., 2019, p. 379).

Finally, we could not discern the effects of different intensities in political ideology of individuals' discussion peers. In this vein, the extent to which individuals are in contact with moderate or extreme leftist or rightist individuals may moderate or amplify the impact of homogeneous social networks on hostile media bias perceptions. For example, Zaller's Receive-Accept-Sample (RAS) model posits that an extremely liberal/conservative individual who encounters moderate liberal/conservative political views may experience "attitude moderation" (Prior, 2013, p. 8), which in turn may downplay perceived hostile media bias. Future studies should account for such nuances. Overall, we believe our findings, albeit context-dependent, contribute to shedding light on the under-researched domain of the social antecedents of hostile media bias perceptions.

\section{References}

Arceneaux, K., Johnson, M., \& Murphy, C. (2012). Polarized political communication, oppositional media hostility, and selective exposure. The Journal of Politics, 74(1), 174-186.

Arpan, L. M., \& Raney, A. A. (2003). An experimental investigation of news source and the hostile media effect. Journalism \& Mass Communication Quarterly, 80(2), 265-281.

Arlt, D., Dalmus, C., \& Metag, J. (2019). Direct and indirect effects of involvement on hostile media perceptions in the context of the refugee crisis in Germany and Switzerland. Mass Communication and Society, 22(2), 171-195.

Bachl, M. (2016). Selective exposure and hostile media perceptions during election campaigns. International Journal of Public Opinion Research, edw014.

Barberá, P., Jost, J. T., Nagler, J., Tucker, J. A., \& Bonneau, R. (2015). Tweeting from left to right: Is online political communication more than an echo chamber? Psychological Science, 26(10), 1531-1542. 
Barnidge, M., \& Rojas, H. (2014). Hostile media perceptions, presumed media influence, and political talk: Expanding the corrective action hypothesis. International Journal of Public Opinion Research, 26(2), 135-156.

Borah, P., Thorson, K., \& Hwang, H. (2015). Causes and consequences of selective exposure among political blog readers: The role of hostile media perception in motivated media use and expressive participation. Journal of Information Technology \& Politics, 12(2), 186-199.

Castro-Herrero, L., Nir, L., \& Skovsgaard, M. (2018). Bridging gaps in cross-cutting media exposure: The role of public service broadcasting. Political Communication, 35(4), 542-565.

Chaffee, S. H. (1982). Mass media and interpersonal channels: Competitive, convergent, or complementary. Inter/media: Interpersonal communication in a media world, 57-77.

Chaffee, S. H., \& Mutz, D. C. (1988). Comparing Mediated and Interpersonal Communication Data. In R. P. Hawkins, J. Wiemann, \& S. Pingree (Eds.), Advancing Communication Science: Merging Mass and Interpersonal Processes (pp. 19-43). Sage.

Coe, K., Tewksbury, D., Bond, B. J., Drogos, K. L., Porter, R. W., Yahn, A., \& Zhang, Y. (2008). Hostile news: Partisan use and perceptions of cable news programming. Journal of Communication, 58(2), 201-219.

Dalton, R. J., Beck, P. A., \& Huckfeldt, R. (1998). Partisan cues and the media: Information flows in the 1992 presidential election. American Political Science Review, 92(01), 111-126.

De Vreese, C. H., \& Boomgaarden, H. G. (2006). Media message flows and interpersonal communication: The conditional nature of effects on public opinion. Communication Research, 33(1), 19-37.

Druckman, J. N., Levendusky, M. S., \& McLain, A. (2018). No Need to Watch: How the Effects of Partisan Media Can Spread via Interpersonal Discussions. American Journal of Political Science, 62(1), 99-112.

Eveland, W. P. (2004). The effect of political discussion in producing informed citizens: The roles of information, motivation, and elaboration. Political Communication, 21(2), 177-193.

Eveland, W. P., \& Hively, M. H. (2009). Political discussion frequency, network size, and "heterogeneity" of discussion as predictors of political knowledge and participation. Journal of Communication, 59(2), 205-224.

Eveland, W. P., \& Shah, D. V. (2003). The impact of individual and interpersonal factors on perceived news media bias. Political Psychology, 24(1), 101-117.

Feldman, L. (2011). Partisan differences in opinionated news perceptions: A test of the hostile media effect. Political Behavior, 33(3), 407-432.

Flanagin, A. J., \& Metzger, M. J. (2000). Perceptions of internet information credibility. Journalism \& Mass Communication Quarterly, 77(3), 515-540.

Flaxman, S., Goel, S., \& Rao, J. M. (2016). Filter bubbles, echo chambers, and online news consumption. Public Opinion Quarterly, 80(S1), 298-320.

Garrett, R. K. (2009). Politically motivated reinforcement seeking: Reframing the selective exposure debate. Journal of Communication, 59(4), 676-699.

Gentzkow, M., \& Shapiro, J. M. (2011). Model appendix: Ideological segregation online and offline.

Giner-Sorolla, R., \& Chaiken, S. (1994). The causes of hostile media judgments. Journal of Experimental Social Psychology, 30(2), 165-180.

Goldman, S. K., \& Mutz, D. C. (2011). The friendly media phenomenon: A cross-national analysis of cross-cutting exposure. Political Communication, 28(1), 42-66. 
Granovetter, M. S. (1973). The Strength of Weak Ties. The American Journal of Sociology, 78(6), 1360-1380.

Guess, A., \& Coppock, A. (2018). Does counter-attitudinal information cause backlash? Results from three large survey experiments. British Journal of Political Science, 1-19.

Gunther, A. C. (1992). Biased press or biased public? Attitudes toward media coverage of social groups. Public Opinion Quarterly, 56(2), 147-167.

Gunther, A. C., \& Christen, C. T. (2002). Projection or persuasive press? Contrary effects of personal opinion and perceived news coverage on estimates of public opinion. Journal of Communication, 52(1), 177-195.

Gunther, A. C., Christen, C. T., Liebhart, J. L., \& Chia, C.-Y. S. (2001). Congenial public, contrary press, and biased estimates of the climate of opinion. Public Opinion Quarterly, 65(3), 295-320.

Gunther, A. C., \& Liebhart, J. L. (2006). Broad reach or biased source? Decomposing the hostile media effect. Journal of Communication, 56(3), 449-466.

Gunther, A. C., \& Schmitt, K. (2004). Mapping boundaries of the hostile media effect. Journal of Communication, 54(1), 55-70.

Gunther, A. C., \& Storey, J. D. (2003). The influence of presumed influence. Journal of Communication, 53(2), 199-215.

Hansen, G. J., \& Kim, H. (2011). Is the media biased against me? A meta-analysis of the hostile media effect research. Communication Research Reports, 28(2), 169-179.

Hardy, B. W., \& Scheufele, D. A. (2005). Examining differential gains from internet use: Comparing the moderating role of talk and online interactions. Journal of Communication, 55(1), 71-84.

Hart, P. S., Feldman, L., Leiserowitz, A., \& Maibach, E. (2015). Extending the impacts of hostile media perceptions: Influences on discussion and opinion polarization in the context of climate change. Science Communication, 37(4), 506-532.

Hartmann, T., \& Tanis, M. (2013). Examining the hostile media effect as an intergroup phenomenon: The role of ingroup identification and status. Journal of Communication, 63(3), 535-555.

Huckfeldt, R. (2001). The social communication of political expertise. American Journal of Political Science, 425-438.

Huckfeldt, R. (2009). Information, Persuasion, and Political Communication Networks. In R. J. Dalton \& H.-D. Klingemann (Eds.), The Oxford Handbook of Political Behavior (pp. 100-122). Oxford University Press.

Huckfeldt, R., Johnson, P. E., \& Sprague, J. (2004). Political disagreement: The survival of diverse opinions within communication networks. New York University Press.

Huge, M., \& Glynn, C. J. (2010). Hostile media and the campaign trail: Perceived media bias in the race for governor. Journal of Communication, 60(1), 165-181.

Hwang, H., Pan, Z., \& Sun, Y. (2008). Influence of hostile media perception on willingness to engage in discursive activities: An examination of mediating role of media indignation. Media Psychology, 11(1), 76-97.

Jost, J. T., Glaser, J., Kruglanski, A. W., \& Sulloway, F. J. (2003). Political conservatism as motivated social cognition. Psychological Bulletin, 129(3), 339.

Kim, M. (2016). The role of partisan sources and audiences' involvement in bias perceptions of controversial news. Media Psychology, 19(2), 203-223.

Klofstad, C. A., McClurg, S. D., \& Rolfe, M. (2009). Measurement of political discussion networks. Public Opinion Quarterly, 73(3), 462-483. 
Lee, T.-T. (2005). The liberal media myth revisited: An examination of factors influencing perceptions of media bias. Journal of Broadcasting \& Electronic Media, 49(1), 43-64.

Matthes, J. (2013). The affective underpinnings of hostile media perceptions: Exploring the distinct effects of affective and cognitive involvement. Communication Research, 40(3), 360-387.

Mutz, D. C. (2002). The consequences of cross-cutting networks for political participation. American Journal of Political Science, 838-855.

Mutz, D. C., \& Martin P. S. (2001). Facilitating communication across lines of political difference: The role of mass media. American Political Science Association, 95(1), 97-114.

Mutz, D. C., \& Mondak, J. J. (2006). The workplace as a context for cross-cutting political discourse. Journal of Politics, 68(1), 140-155.

Nir, L. (2012). Cross-national differences in political discussion: Can political systems narrow deliberation gaps? Journal of Communication, 62(3), 553-570.

Oh, H. J., Park, J., \& Wanta, W. (2011). Exploring factors in the hostile media perception: Partisanship, electoral engagement, and media use patterns. Journalism \& Mass Communication Quarterly, 88(1), 40-54.

Perloff, R. M. (2015). A three-decade retrospective on the hostile media effect. Mass Communication and Society, 18(6), 701-729.

Price, V., Cappella, J. N., \& Nir, L. (2002). Does disagreement contribute to more deliberative opinion?. Political communication, 19(1), 95-112.

Prior, M. (2013). Media and political polarization. Annual Review of Political Science, 16, 101-127.

Rattinger, H., Roßteutscher, S., Schmitt-Beck, R., Weßels, B., Wolf, C., \& Partheymüller, J. (2014). Rolling cross-section campaign survey with post-election panel wave (GLES

2013). ZA5703 data file version, $2(0)$.

Reinemann, C., Stanyer, J., \& Scherr, S. (2016). Hard and soft news. In C. de Vreese, F. Esser \& D.N. Hopmann (Eds.), Comparing Political Journalism (pp. 131-168). London: Routledge

Reid, S. A. (2012). A self-categorization explanation for the hostile media effect. Journal of Communication, 62(3), 381-399.

Robinson, M. J. (1976). Public Affairs Television and the Growth of Political Malaise: The Case of 'The Selling of the Pentagon'. The American Political Science Review, 70(2), 409-432.

Rojas, H. (2010). “Corrective” actions in the public sphere: How perceptions of media and media effects shape political behaviors. International Journal of Public Opinion Research, 22(3), 343-363.

Rojas, H., Barnidge, M., \& Abril, E. P. (2016). Egocentric publics and corrective action. Communication and the Public, 1(1), 27-38.

Ross, L., Greene, D., \& House, P. (1977). The "false consensus effect": An egocentric bias in social perception and attribution processes. Journal of Experimental Social Psychology, 13(3), 279-301.

Savage, J. (2004). Does viewing violent media really cause criminal violence? A methodological review. Aggression and Violent Behavior, 10(1), 99-128.

Schmitt, K. M., Gunther, A. C., \& Liebhart, J. L. (2004). Why partisans see mass media as biased. Communication Research, 31(6), 623-641.

Schmitt-Beck, R., \& Lup, O. (2013). Seeking the soul of democracy: A review of recent research into citizens' political talk culture. Swiss Political Science Review, 19(4), 513-538.

Schönbach, K., Ridder, J., \& Lauf, E. (2001). Politicians on TV news: Getting attention in Dutch and German election campaigns. European Journal of Political Research, 39(4), 519-531. 
Schönbach, K., \& Semetko, H. A. (2000). “Gnadenlos professionell”: Journalisten und die aktuelle Medienberichterstattung in Bundestagswahlkämpfen 1976-1998 [“Mercilessly professional”: Journalists and the media coverage during national elections 1976-1998]. In Wahlen und Politikvermittlung durch Massenmedien (pp. 69-78). Springer.

Sidanius, J. (1985). Cognitive functioning and sociopolitical ideology revisited. Political Psychology, 637-661.

Strömbäck, J., \& Dimitrova, D. V. (2006). Political and media systems matter: A comparison of election news coverage in Sweden and the United States. Harvard International Journal of Press/Politics, 11(4), 131-147.

Taber, C. S., \& Lodge, M. (2006). Motivated skepticism in the evaluation of political beliefs. American Journal of Political Science, 50(3), 755-769.

Theocharis, Y., Barberá, P., Fazekas, Z., Popa, S. A., \& Parnet, O. (2016). A bad workman blames his tweets: The consequences of citizens' uncivil Twitter use when interacting with party candidates. Journal of Communication, 66(6), 1007-1031.

Tsfati, Y. (2007). Hostile media perceptions, presumed media influence, and minority alienation: The case of Arabs in Israel. Journal of Communication, 57(4), 632-651.

Tsfati, Y., \& Cohen, J. (2005). The influence of presumed media influence on democratic legitimacy: The case of Gaza settlers. Communication Research, 32(6), 794-821.

Vallone, R. P., Ross, L., \& Lepper, M. R. (1985). The hostile media phenomenon: Biased perception and perceptions of media bias in coverage of the Beirut massacre. Journal of Personality and Social Psychology, 49(3), 577.

Watts, M. D., Domke, D., Shah, D. V., \& Fan, D. P. (1999). Elite cues and media bias in presidential campaigns: Explaining public perceptions of a liberal press. Communication Research, 26(2), 144-175.

Weeks, B. E., Kim, D. H., Hahn, L. B., Diehl, T. H., \& Kwak, N. (2019). Hostile media perceptions in the age of social media: Following politicians, emotions, and perceptions of media bias. Journal of Broadcasting \& Electronic Media, 63(3), 374-392.

Wessler, H., \& Rinke, E. M. (2014). Deliberative performance of television news in three types of democracy: Insights from the United States, Germany, and Russia: Deliberative news performance. Journal of Communication, 64(5), 827-851. https://doi.org/10.1111/ jcom.12115

Wojcieszak, M. (2017). Hostile public effect: Minority status mobilizing political participation. International Journal of Public Opinion Research, 29(1), 46-69.

Yair, O., \& Sulitzeanu-Kenan, R. (2015). Biased judgment of political bias: Perceived ideological distance increases perceptions of political bias. Political Behavior, 37(2), 487-507.

Zaller, J. R. (1992). The nature and origins of mass opinion. Cambridge University Press. 


\section{Appendix}

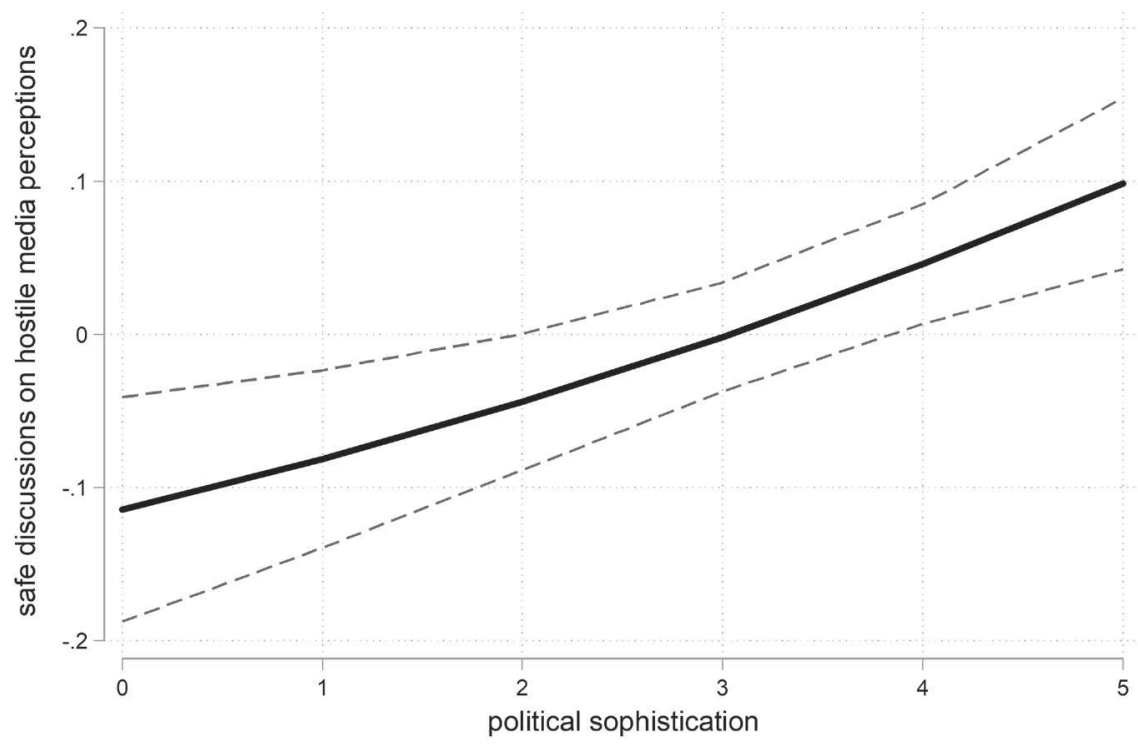

Figure 2: Average marginal effects of safety of political discussions on hostile media bias perceptions, by levels of political sophistication.

Note: Effect sizes on hostile media perceptions for each level of sophistication with $95 \% \mathrm{Cl}$.

\section{Question wording and coding of variables}

\section{Hostile media bias perceptions}

Many people in Germany are inclined to support a particular political party for a longer period of time even if they occasionally vote for another party. What about you? In general terms, are you inclined to support a particular political party? And if so, which one?

(If BILD is read at least once a week) If you think about the reports on political parties in BILD during the election campaign, which impression did you have? Were these reports more favorable to some parties than to others? If yes, to which parties? (up to 3 parties in the order mentioned) 
(If outlet read/watched at least once a week) If you think about the reports in this newspaper on/coverage in these programs of the political parties during the election campaign, which impression did you have? Were these reports more favorable to some parties than to others? If so, to which parties?

\section{Ideology}

Do you see yourself as a rather left-wing or a rather right-wing person? Please use a scale from 1 to 11 . If 1 is "left" and 11 is "right", where do you see yourself?

\section{Strength of party identification}

(If inclined to support a particular party) How strongly or little are you inclined to support this party: very strongly, fairly strongly, moderately, fairly little, or very little? (re-coded $0=$ no party ID, 6=very strong party ID)

\section{Political sophistication (additive index of knowledge and interest)}

In the federal election, you have two votes: the first vote and the second vote. Which one of the two is decisive for the relative strengths of the parties in the Bundestag?

1-3 multiple choice with one-true option and DK. Correct answer 1 point)

Generally, how interested in politics are you? 5-point scale

\section{News media attention}

(If TV was watched on at least one day) When you were watching the news on television, how carefully did you watch the reports on the political parties and the election campaign - very carefully, carefully, not so carefully, or not carefully at all? 4-point inverted scale, reverse-coded

(If newspaper read at least one day) How carefully did you read reports on the parties and the election campaign - very carefully, carefully, not so carefully, or not carefully at all? 4-point scale, reverse-coded 


\section{Frequency of political discussions}

On how many days last week did you talk about politics and the political parties with other people, such as members of your family, friends, or acquaintances? (0-7)

\section{Network size}

(If person discussed politics 1-7) What would you say, what was the number of persons with whom you talked about politics? $0=$ no discussions, $21=$ more than 20 persons

\section{Discussion safety/danger:}

Are you inclined to support a particular political party? And if so, which one?

On how many days last week did you talk to this person (first discussion partner/second discussion partner) about parties or the federal election? (0-7)

Which party do you think this person (first discussion partner/second discussion partner) will probably vote for in the federal election on 22 September, or do you think she/he will not vote at all?

\section{Example of how hostile media perceptions (or HMP) is constructed}

To illustrate the computation of hostile media bias perceptions (or HMP), two hypothetical individuals (individual $x$ and individual $y$ ) will be used as examples. Individual $x$ is an SPD-supporter, who reads Bild and watches ZDF, and individual $y$ is a CDU/CSU supporter, who also reads Bild and watches ZDF. Both individual $x$ and individual $y$ perceive Bild and ZDF to lean towards CDU/CSU. Accordingly, we first assign a left $=1$ to individual $x$ since she/he votes SPD and assign a right $=1$ to individual $y$ since she/he votes CDU/CSU. Second, we compute an average perceived ideology of each individual's media diet on a 3-point scale where 1=leftist, $2=$ neutral, $3=$ rightist. As both individual $x$ and individual $y$ perceive the media outlets they use as favoring CDU/CSU, each of these individuals' perceived media ideology scores 3. Third and last, an HMP value of 1 is assigned to individual $x$, who voted for a leftist party (SPD) and perceived her media diet as favoring the opposing political camp (CDU/CSU or right), and an HMP value of -1 is assigned 
to individual $y$, since she/he voted for a rightist party and perceived her frequent media diet as close to her political camp (right). 